\title{
Axonal Dopamine Receptors Activate Peripheral Spike Initiation in a Stomatogastric Motor Neuron
}

\author{
Dirk Bucher, Vatsala Thirumalai, and Eve Marder \\ Volen Center and Biology Department, Brandeis University, Waltham, Massachusetts 02454-9110
}

We studied the effects of dopamine on the stomatogastric ganglion (STG) of the lobster, Homarus americanus. The two pyloric dilator (PD) neurons are active in the pyloric rhythm, have somata in the STG, and send axons many centimeters to innervate muscles of the stomach. Dopamine application to the stomatogastric nervous system when the PD neurons were rhythmically active evoked additional action potentials during the PD neuron interburst intervals. These action potentials were peripherally generated at a region between the STG and the first bilateral branch, $\sim 1 \mathrm{~cm}$ away from the STG, and traveled antidromically to the neuropil and orthodromically to the pyloric dilator muscles. Focal applications of dopamine to the nerves showed that spikes could be initiated in almost the entire peripheral axon of the PD neurons. Dopamine also evoked spikes in isolated peripheral axons. The concentration threshold for peripheral spike initiation was at or below $10^{-9} \mathrm{M}$ dopamine. Thus, the peripheral axon can play an important role in shaping the output signaling to the muscles by the motor neuron.

Key words: crustacean; Homarus americanus; antidromic spikes; backpropagation; stomatogastric ganglion; neuromodulation; neurohormones

\section{Introduction}

The sole function commonly ascribed to axons is the conduction of action potentials between physically and electrotonically distant sites. Motor neuron axons usually faithfully transmit action potentials from a somatic/dendritic integration site to a distant muscle target. Most axons are thought to have a relatively simple complement of voltage-activated currents (Hodgkin and Huxley, 1952; Connor et al., 1977), those minimally required for action potential propagation. Nonetheless, there are examples of motor axons that show more complex intrinsic properties. In the cat soleus nerve, a post-tetanic single stimulus can induce repetitive firing that is generated close to the terminals of the motor neuron axons and is thought to be the cause of post-tetanic potentiation in the soleus muscle (Standaert, 1963, 1964). In leech segmental heart motor neurons, the peripheral axons are capable of producing bursts when central activity is suppressed (Maranto and Calabrese, 1983). In the stick insect, a single leg motor axon produces bursting when the leg is autotomized and the axon is severed from the central part of the neuron (Bässler, 1984; Schmidt and Grund, 2001).

Synaptic release at axon terminals of crustacean neuromuscular junctions can be modulated (Dudel, 1965), and modulators

\footnotetext{
Received March 24, 2003; revised June 11, 2003 ; accepted June 13, 2003.

This work was supported by National Institute of Neurological Disorders and Stroke Grant NS17813 (E.M.) and Stipend BU 1361/1-1 of the Deutsche Forschungsgemeinschaft (D.B.).We thank Kristina Rehm and Stefan Pulver for help with some of the initial experiments, Astrid Prinz for stimulating discussions, and Ralph DiCaprio for his hospitality and help with Spike2 programming.

Correspondence should be addressed to Dr. Dirk Bucher, Volen Center, MS 013, Brandeis University, 415 South Street, Waltham, MA 02454-9110. E-mail: bucher@brandeis.edu.

V. Thirumalai's present address: Beckman Building, Cold Spring Harbor Laboratory, 1 Bungtown Road, P.O. Box 100, Cold Spring Harbor, NY 11724

Copyright $\odot 2003$ Society for Neuroscience $\quad$ 0270-6474/03/236866-10\$15.00/0
}

can elicit spontaneous nerve terminal activity (Grundfest and Reuben, 1961), but apart from their terminals motor axons are not usually thought to be chemosensitive. However, the lateral gastric (LG) motor neuron in the crab stomatogastric ganglion (STG) has peripheral spike initiation zones at a considerable distance from its target muscles that generate prolonged tonic spiking in the presence of serotonin in response to centrally generated bursts (Meyrand et al., 1992). In this case, the serotonin-sensitive peripheral spike-initiation zone is close enough electrotonically to be under the control of depolarization from the soma and primary neurites of the LG neuron in the STG, and serotonin is thought to be released at specific sites in the nerve from sensory terminals of muscle receptors.

The stomatogastric nervous system that controls movements of the stomach of decapod crustaceans is modulated by a multitude of peptides, biogenic amines, and conventional transmitters. These are either released from modulatory terminals or from neurohemal organs into the hemolymph (Marder, 1987; HarrisWarrick et al., 1992; Christie et al., 1995; Marder et al., 1995; Marder and Calabrese, 1996; Marder and Bucher, 2001). Among them, dopamine was one of the first neuromodulators described (Kushner and Maynard, 1977; Barker et al., 1979; Kushner and Barker, 1983; Cournil et al., 1994, 1995). In H. americanus dopamine is found in both defined neuronal projections to the STG, as well as in the pericardial organs, the major neurosecretory organ that provides hormonal modulation to the stomach and stomatogastric nervous system (Sullivan, 1978; Pulver et al., 2003).

We now show that in the lobster Homarus americanus hormonal concentrations of dopamine act on the axons of the pyloric dilator (PD) neurons to elicit spikes. These actions are different from the well characterized effects dopamine has on the pyloric rhythm of the STG of the spiny lobster, Panulirus inter- 


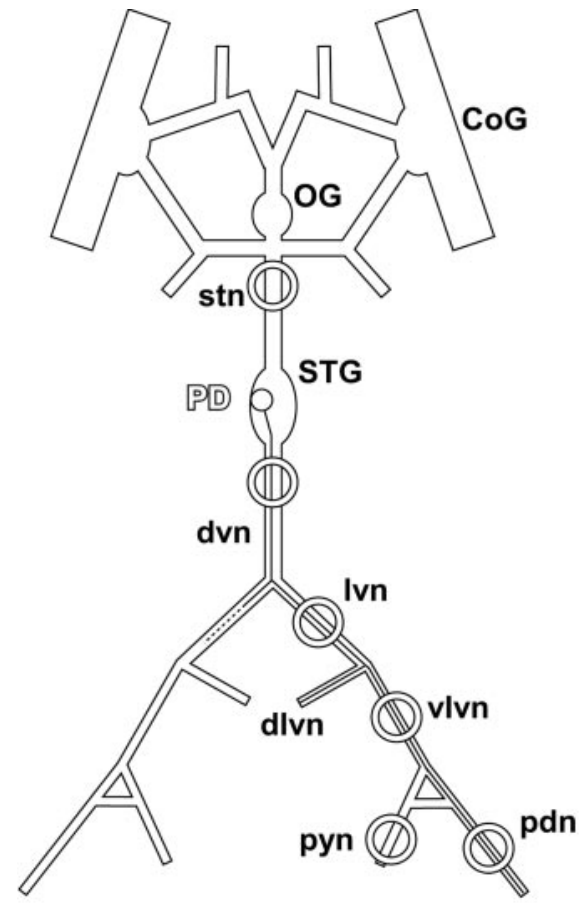

Figure 1. The stomatogastric nervous system. The main axonal branching pattern for one of the two PD neurons is shown on one side. The dlvn was always cut close to its origin. Rings indicate sites of petroleum jelly wells. The well on the stn was used to block impulse activity by the application of TTX/sucrose. The well on the dvn was either used for extracellular recording or for blocking impulse activity with TTX/sucrose. dvn, Ivn, vlvn, and pdn wells were used for the focal application of dopamine and for extracellular recording. pyn, Pyloric nerve. Nomenclature after Maynard and Dando (1974).

ruptus (Ayali and Harris-Warrick, 1998, 1999; Ayali et al., 1998; Harris-Warrick et al., 1998; Kloppenburg et al., 1999, 2000; Peck et al., 2001). These data indicate that a neuromodulator or hormone can be sufficient to elicit spiking in a large axonal region of a neuron, and this may play an integral role in shaping the synaptic output of this neuron.

\section{Materials and Methods}

Adult Homarus americanus $(n=38)$ were obtained from Commercial Lobster (Boston, MA) and kept in artificial seawater tanks at $11^{\circ} \mathrm{C}$. Lobsters were anesthetized by keeping them on ice for $15 \mathrm{~min}$ before dissection. The stomatogastric nervous system (Fig. 1), consisting of the paired commissural ganglia (CoGs), esophageal ganglion (OG), the STG, their connectives and some of the motor nerves, was dissected and pinned out in a transparent Sylgard-coated (Dow Corning, Midland, MI) dish containing chilled $\left(9-13^{\circ} \mathrm{C}\right)$ saline. The saline solution consisted of the following (in mM): $479.12 \mathrm{NaCl}, 12.74 \mathrm{KCl}, 13.67 \mathrm{CaCl}_{2}, 20 \mathrm{MgSO}_{4}, 3.91$ $\mathrm{Na}_{2} \mathrm{SO}_{4}$, and 5 HEPES, pH 7.45 .

Electrophysiological recordings and pharmacological applications. For electrophysiological recordings, the STG was desheathed, and petroleum jelly (Vaseline) wells were placed on the motor nerves. Extracellular recordings from the nerves were made by placing stainless steel pin electrodes in the wells. Signals were amplified and filtered using a differential AC amplifier (A-M Systems, Carlsborg, WA). Intracellular recordings from the STG motor neuron somata were made using 20-40 M $\Omega$ glass microelectrodes filled with $0.6 \mathrm{M} \mathrm{K}_{2} \mathrm{SO}_{4}$ and $20 \mathrm{~mm} \mathrm{KCl}$ and an Axoclamp 2B amplifier (Axon Instruments, Foster City, CA). Pyloric motor neurons were identified using standard procedures (Selverston and Moulins, 1987). When appropriate, the STG was isolated from descending inputs from the CoGs and OG by blocking action potential conduction in the stomatogastric nerve (stn) with $750 \mathrm{~mm}$ sucrose and $1 \mu \mathrm{M}$ TTX in a petroleum jelly well on the stn. In some experiments, the peripheral nerves were isolated from central activity by blocking the dorsal ventric- ular nerve (dvn) close to the STG (Fig. 1). During recordings, the preparations were continuously superfused with chilled $\left(12^{\circ} \mathrm{C}\right)$ physiological saline, and dopamine (3-hydroxytyramine hydrochloride; Sigma, St. Louis, MO) containing saline at indicated concentrations was introduced into the bath using a switching manifold. Dopamine stock solutions were freshly made and kept on ice for no longer than $1 \mathrm{hr}$ to avoid degradation.

Data acquisition and analysis. Data were acquired using a Digidata 1200 data acquisition board (Axon Instruments) and subsequently converted and analyzed in Spike2 (version 4; Cambridge Electronic Design, Cambridge, UK) using programs written in the Spike2 script language. Analyzed data were plotted, and statistical tests were performed in Statview (version 5; SAS Institute, Cary, NC). Final figure mounting was done in Canvas (version 8; Deneba Systems, Miami, FL). Because the recording wells had inner diameters of $>1 \mathrm{~mm}$, extracellularly recorded spikes have complex waveforms produced as the spikes travel on the section of nerve in the well. Spike detection was done either by simple voltage thresholding or by using the spike shape template functions in Spike2. Changes in the cycle period of the pyloric rhythm were analyzed. The cycle period was defined as the time from the first spike in a burst of the PD neuron to the first spike in the next burst. In some cases, there was too much tonic spiking activity to define bursts reliably. In these cases, spikes in the intracellular recording trace of the PD neuron were eliminated using a sliding average smoothing function in Spike2; the cycle period was then determined from the time between peaks of the slowwave membrane oscillation of the PD neuron.

Data are presented here as plots of the cycle frequency (the inverse of the cycle period). However, an inverse operation changes the variance of the sample; therefore, paired $t$ tests for statistical significance were performed on the cycle periods. For quantification, cycle frequencies or periods were always plotted first over time. Time stretches of several minutes in which the range of values did not change visibly were assumed to represent the steady state and were used to determine means.

Mean spike frequencies showed large variations between different experiments. Therefore, nonparametric tests were used to establish statistical difference (Spearman rank correlation test, Friedman test, and Wilcoxon signed rank test, as indicated). In all cases, statistical significance was assumed at $p<0.05$. Statistical significance is indicated in bar plots by asterisks $\left({ }^{\star} p<0.05 ;{ }^{* *} p<0.01\right)$.

\section{Results}

The pyloric rhythm is produced by a well characterized small group of neurons in the STG (Selverston and Moulins, 1987; Harris-Warrick et al., 1992). The two PD neurons, together with the anterior burster $(\mathrm{AB})$ interneuron, form the pacemaker kernel of the pyloric rhythm. The AB and PD neurons are electrically coupled and make inhibitory chemical synapses onto a number of follower neurons, including the lateral pyloric (LP) neuron and the pyloric (PY) neurons. Feedback from follower neurons to the pacemaker kernel is restricted to an inhibitory chemical synapse from the LP neuron to the PD neurons. The axonal branching pattern of one of the PD neurons is depicted schematically in Figure 1 (Maynard and Dando, 1974). The PD neuron somata are in the STG, and their axons exit the ganglion via the unpaired dorsal ventricular nerve ( dvn), before splitting into the paired lateral ventricular nerves (lvns). The PD axons divide again into both the ventral and the dorsal branches of the lvn (vlvn, dlvn) to innervate two different sets of muscles. The dlvn leads to the anterior dorsal pyloric dilator muscles, and the vlvn ends in the pyloric dilator nerve $(\mathrm{pdn})$ that innervates the ventral pyloric dilator muscles (Maynard and Dando, 1974). In the experiments reported here, the dlvn branches were not retained during the dissection, and PD neuron activity was monitored in recordings from the dvn, lvn, vlvn and pdn. 
Dopamine elicited tonic "extraburst" spiking in PD neurons and increased the cycle frequency of the pyloric rhythm

In $\mathrm{H}$. americanus, when the modulatory input from the CoGs and the OG to the STG is removed by blocking impulse activity in the stn, the $\mathrm{AB}$ and the two PD neurons continue to cycle at a low frequency, whereas the LP and PY follower neurons fall silent (Thirumalai and Marder, 2002) (Fig. 2A). Intracellular recordings of the PD neurons show slow-wave membrane oscillations with bursts of spikes during the depolarized phase of the slow wave. Bath application of $10^{-6} \mathrm{M}$ dopamine to the entire preparation elicited "extraburst" spikes during the interburst interval in seven of eight experiments (Fig. $2 B-D$ ). These spikes were not riding on top of any apparent EPSPs. At the onset of this effect, the extraburst spikes appeared late in the interburst interval (Fig. $2 B$ ). Later in dopamine application, extraburst spiking had a regular tonic frequency throughout the interburst interval (Fig. $2 C)$. Still later in dopamine application, the spike rate became regular and the slow-wave membrane oscillation ceased or was significantly reduced (Fig. 2D).

In P. interruptus, the application of dopamine in preparations with the stn blocked does not elicit extraburst spikes, but does have effects on the frequency of the pyloric rhythm (Flamm and Harris-Warrick, 1986a; Ayali and Harris-Warrick, 1999). Figure 2 shows clearly that there were dramatic increases in the pyloric rhythm frequency until these were overwhelmed by the burst suppression late in dopamine applications. In four of the preparations, there was a long enough time before the burst was suppressed to allow us to quantify burst frequency from a comparatively stable data window. In these experiments, the increase in cycle frequency was nearly threefold (Fig. 2E). It should be noted that this effect was at least partly independent of the presence of extraburst spikes. The first extraburst spike in the PD recording in Figure $2 B$ is the actual first extraburst spike recorded in response to the dopamine application. By that time, the cycle frequency had already increased by a factor of $\sim 2.5$.

The increased burst frequency seen in dopamine was accompanied by a small depolarization of the PD neurons and a slight hyperpolarization of the LP neuron (Fig. 2C,D). Because these neurons release transmitter as a graded function of membrane potential and are reciprocally inhibitory (Fig. $2 F$ ) (Russell and Graubard, 1987; Hartline and Graubard, 1992), it is not possible from these experiments alone to determine whether either or both of the neurons is a direct target of the dopamine action.

These initial results led us to ask where the extraburst spikes were generated. They appeared in soma recordings of the PD neurons without any visible underlying depolarization, and at membrane potentials significantly lower than the threshold for spike initiation seen in soma recordings for burst-associated spikes. This suggested that the initiation site for extraburst spikes could be far more distant from the soma than the one for spikes that ride on top of the slow depolarizing waves.

Extraburst spikes are generated in the peripheral axons of PD To determine the origin of extraburst spike activity, we placed petroleum jelly wells on the peripheral motor nerves at different locations (as indicated in Fig. 1), bath-applied $10^{-6} \mathrm{M}$ dopamine, and recorded nerve activity simultaneously while recording intracellularly from the PD neuron soma. Multiple sweeps of recording traces were triggered on the peak of the intracellular somatic spike. These recordings show different propagation delays for spikes during bursts and spikes during interburst intervals (Fig. 3). Burst spikes (Fig. 3A), which were presumably generated in the STG neuropil, reached the upper dvn and the soma

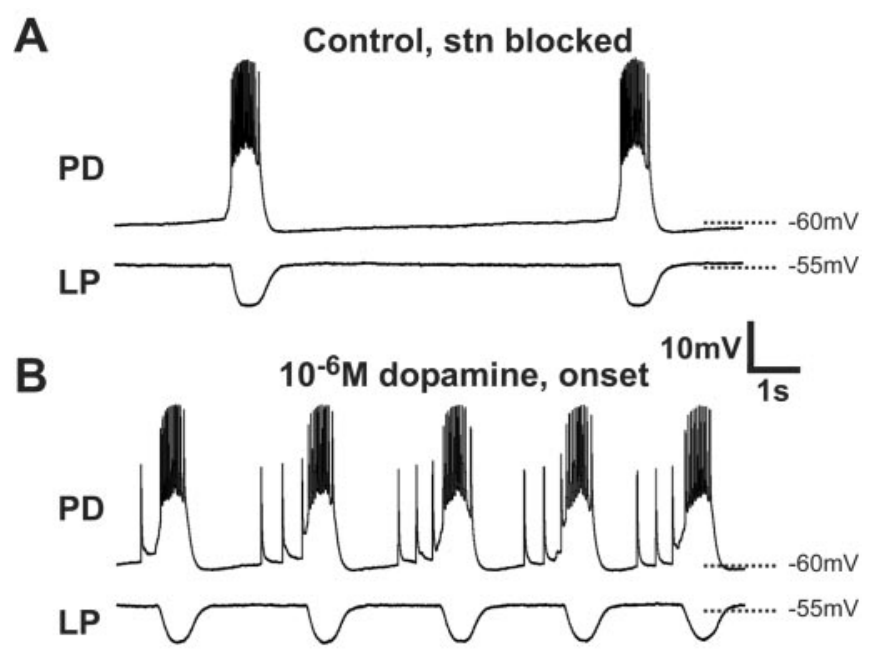

C $10^{-6} \mathrm{M}$ dopamine, $2 \mathrm{~min}$

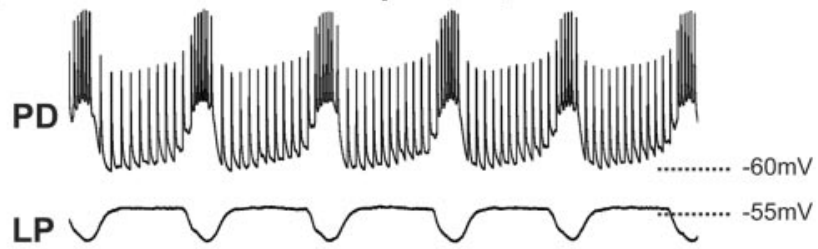

D $10^{-6} \mathrm{M}$ dopamine, $10 \mathrm{~min}$

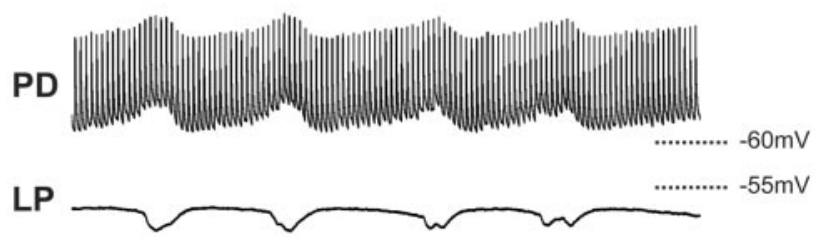

E

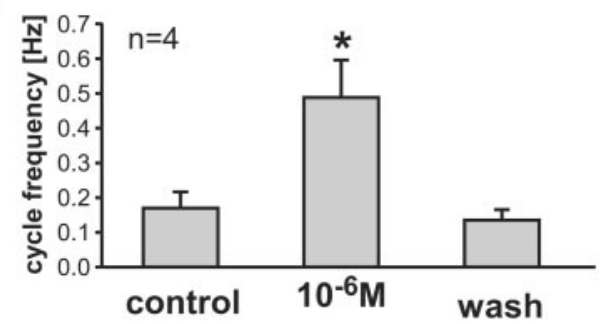

$\mathbf{F}$

Figure 2. Dopamine actions on the STG. Dopamine $\left(10^{-6} \mathrm{M}\right)$ was bath-applied to the STG after modulatory inputs from the $\mathrm{CGS}$ and the $\mathrm{OG}$ were removed by blocking impulse activity in the stn with a TTX/sucrose well. Simultaneous intracellular recordings from the soma of a PD neuron and the lateral pyloric ( $L P$ ) neuron are shown. $A$, Control saline. $B$, Immediately after the onset of extraburst spiking in $10^{-6} \mathrm{M}$ dopamine. Extraburst spikes were seen late in the interburst interval. C, Two minutes in $10^{-6} \mathrm{M}$ dopamine. D, Ten minutes in $10^{-6} \mathrm{M}$ dopamine. $E$, Mean pyloric cycle frequencies for four preparations. The cycle frequency in dopamine is significantly different from the control ( $p<0.02$, paired $t$ test). Data are means \pm SD. F, Connectivity diagram showing reciprocal inhibitory connections (filled circles) between PD neurons and LP.

at approximately the same time and traveled down the peripheral axons to the pdn with a delay of $31-40 \mathrm{msec}(34.3 \pm 3.4 \mathrm{msec}$, $n=6$ ) from the peak of the spike in the intracellular soma recording. Extraburst spikes (Fig. 3B) appeared first in the dvn and reached the lvn earlier than the soma. The delay between the spike in the soma and in the pdn was only $8-15 \mathrm{msec}(11.8 \pm 2.8 \mathrm{msec})$. 


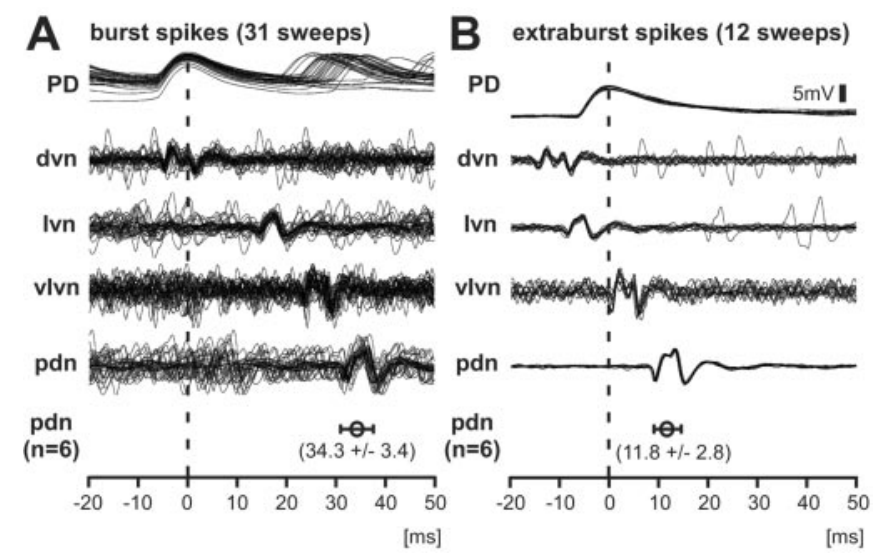

Figure 3. Dopamine-evoked extraburst spikes are peripherally initiated. The peaks of spikes in the intracellular soma recordings (vertical dashed line) were used to trigger multiple sweeps of nerve recordings. A, Burst spikes initiated in the STG reached the soma and the dvn at approximately the same time and traveled with increasing delay down the lvn and vlvn to the $p d n$. The mean delay \pm SD between the soma and the pdn was $34.3 \pm 3.4 \operatorname{msec}(n=6)$. $B$, Extraburst spikes appeared first in the dvn, then in the lvn, and then in the soma. The delay between dvn and lvn was much shorter than in burst spikes, indicating a spike initiation zone between the dvn and lvn recording sites. The mean delay between soma and pdn was $11.8 \pm$ $2.8 \mathrm{msec}(n=6)$. The delays in $A$ and $B$ were statistically different (paired $t$ test, $p<0.001$ ).

These two delays were statistically different (paired $t$ test, $p<$ 0.001), indicating different sites of spike initiation.

Where were the extraburst spikes initiated? The conduction delay between upper dvn and lvn recording sites for these spikes was much shorter than for spikes occurring during bursts. This indicates that the extraburst spikes were generated peripherally, somewhere between the upper dvn and lvn, distal to the dvn recording site and proximal to the lvn recording site. They traveled both up to the STG, where they invaded the neuropil and soma antidromically, and down toward the pdn. If similar spike conduction velocities in both directions are assumed, the conduction delay between the two spike initiation sites can be roughly calculated. Spikes generated in the periphery passed the $\mathrm{dvn}$ recording site and invaded the soma $\sim 10 \mathrm{msec}$ later. Because there was no delay between the dvn recording site and the soma for spikes generated during bursts, the delay between the central spike initiation site and the dvn was $\sim 5 \mathrm{msec}$. Centrally generated spikes passed the dvn and reached the lvn $\sim 20$ msec later, whereas spikes generated between the dvn and the lvn also reached the dvn first but the lvn only $\sim 7 \mathrm{msec}$ later. The conduction time between the dvn and the lvn for centrally generated spikes equals the sum of the conduction times from the peripheral spike initiation site to both dvn and lvn recording sites. The delay between the dvn and the lvn for peripherally generated spikes equals the difference between the conduction times from the peripheral spike initiation zone to the lvn and the peripheral spike initiation zone to the dvn. Therefore, the peripherally generated spike needed $\sim 7 \mathrm{msec}$ to reach the dvn recording site and the conduction delay between central and peripheral spike initiation site was $\sim 12 \mathrm{msec}$.

Did spike extinction by the collision of orthodromic and antidromic spikes alter the activity pattern of the PD neuron axons? The $12 \mathrm{msec}$ delay between central and peripheral spike initiation sites was much shorter than even the minimal interspike intervals that we found during the application of $10^{-6} \mathrm{M}$ dopamine for spikes during bursts $(\sim 40 \mathrm{msec})$ and extraburst spikes $(\sim 100$ $\mathrm{msec}$ ). Therefore, the probability for spike collisions was low, and roughly the same spike patterns were conveyed to the soma and
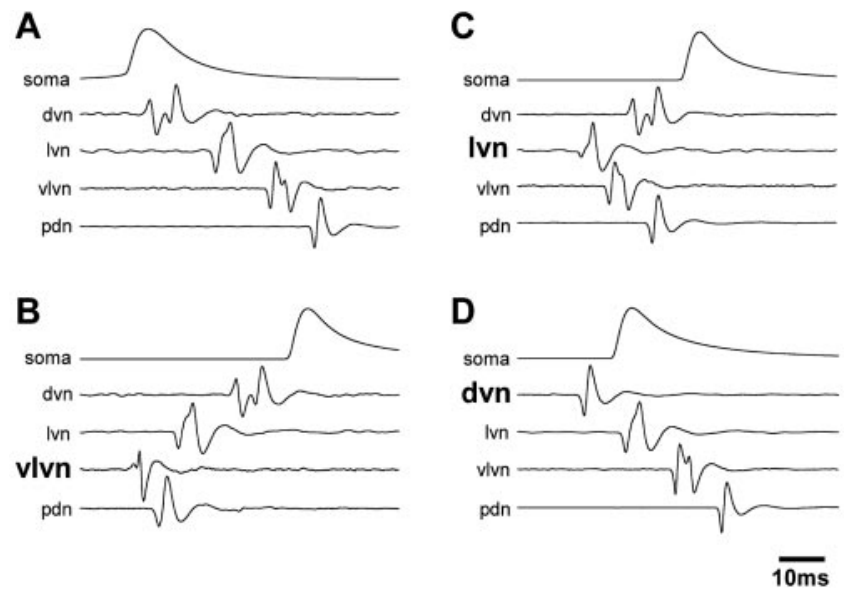

Figure 4. A large portion of the PD axon is dopamine-sensitive. Intracellular spikes were used to trigger multiple sweeps of data; $100-500$ sweeps were averaged. Petroleum jelly wells were located as indicated in Figure 1, except the dvn recording site was more distal in this experiment. The site of dopamine application is indicated in bold. $A$, Control. Spikes first reached the soma and then the dvn, from which they traveled orthodromically down the nerves toward the PD innervated muscles. $B, 10^{-4} \mathrm{M}$ dopamine applied to the vlvn well. $C, 10^{-4} \mathrm{M}$ dopamine applied to the Ivn well. $D, 10^{-4} \mathrm{M}$ dopamine applied to the dvn well. Slight changes in the spike waveform in the extracellular recordings were attributable to the repeated exchange of fluid in the recording wells.

the muscles. In fact, pdn recordings showed a very similar spike pattern compared with the soma (data not shown), but a one-toone match of spikes was difficult because the pdn recordings contained spikes generated by the axons of both PD neurons.

In experiments in which dopamine was bath-applied to the whole preparation the site of the peripheral spike initiation invariably appeared to be in the lower dvn (somewhere between the upper dvn and the upper lvn, $\sim 1 \mathrm{~cm}$ from the STG). However, we also wanted to determine which sites of the peripheral nerves were potentially capable of spike initiation in dopamine. Therefore, we made small petroleum jelly wells (inside diameter, $\sim 1$ $\mathrm{mm}$ ) at multiple sites along the nerves and used these to both record from those sites and to apply high concentrations of dopamine $\left(10^{-4}\right.$ to $\left.10^{-3} \mathrm{M}\right)$ to these small sections of nerve. Figure 4 shows results from one of four experiments in which dopamine was sequentially applied to different wells so that the site of dopamine sensitivity could be assessed. The traces are averages of 100-500 sweeps triggered by the intracellular spikes. In these experiments, dopamine applied to several wells was effective; in each case, the site of spike initiation moved when the site of dopamine application was changed. In all four experiments, dopamine applications to wells placed on any portion of the lvn, vln ,or dvn were effective in triggering spikes, although wells on the pdn were not. The nerve name in boldface type (Fig. 4) shows where the well with the dopamine was placed. The spikes appeared first in the well containing dopamine and then traveled antidromically toward the soma and orthodromically toward the periphery.

\section{Dopamine elicits spikes in peripheral PD axons at hormonal concentrations}

Tyrosine hydroxylase immunohistochemistry shows no staining in the peripheral stomatogastric nerves (Pulver et al., 2003). This suggests that dopamine is not present in terminals within the peripheral nerves and can reach the peripheral PD axons only via the hemolymph, and at hormonal concentrations. Therefore, we 
also wanted to determine if low concentrations of dopamine would be sufficient to initiate spiking in the peripheral PD axons.

To simplify these experiments, we wished to study spike initiation in the periphery in the absence of centrally generated spikes initiated in the STG. Therefore, in 15 experiments we blocked spike conduction in the upper dvn with a TTX/sucrose well, and recorded in control saline and in the presence of dopamine at varying concentrations. Figure $5 A$ shows an intracellular recording of the PD neuron (upper trace), cycling at a normal frequency. With the dvn blocked, spikes generated in the STG were not conducted to the periphery; therefore, they were not seen in the pdn recording (lower trace). Instead, in the absence of orthodromic spikes, the isolated PD axons in 8 of 15 experiments were spontaneously active, either tonically $(n=2)$ or in irregular bursts $(n=6)$. The mean overall spike frequency was $0.64 \pm 0.49$ $\mathrm{Hz}(n=8$, ranging from 0.15 to $1.39 \mathrm{~Hz})$ and the mean burst frequency was $0.14 \pm 0.12 \mathrm{~Hz}(n=6$, ranging from 0.03 to 0.32 $\mathrm{Hz}$ ).

In the top trace of Figure $5 B$, the two PD axon spikes can be distinguished by their amplitudes in the pdn recording. They were both active, but no longer synchronous, because their axons were spontaneously and independently bursting in control saline. The second trace in Figure $5 B$ shows the response to $10^{-9} \mathrm{M}$ dopamine; both axons went from slow bursts to rapid tonic activity. At $10^{-6} \mathrm{M}$ dopamine (third trace) both axons fired still faster.

In 12 of the 15 experiments, we applied dopamine at both $10^{-10}$ and $10^{-9} \mathrm{M}$. In each experiment, spike frequencies were measured in control saline and in the last $5 \mathrm{~min}$ of a $15 \mathrm{~min}$ dopamine application. In 9 of 12 experiments $10^{-10} \mathrm{M}$ dopamine increased spike frequency and in 11 of 12 experiments $10^{-9} \mathrm{M}$ dopamine increased spike frequency, indicating that the threshold for dopamine action, although difficult to establish exactly, is consistent with dopamine acting at concentrations expected to occur hormonally. The data from all 12 experiments with both concentrations were pooled (Fig. 5C). Analysis of these data showed a dose-dependent effect of dopamine application $(p<$ 0.001, Friedman test).

It was not possible to do complete dose-response curves for dopamine action because we saw considerable long-lasting desensitization at $10^{-6} \mathrm{M}$ dopamine and higher (data not shown). Nonetheless, we saw no statistical difference between preparations for which $10^{-9} \mathrm{M}$ was the first application and those for which $10^{-9} \mathrm{M}$ application was followed the application of lower concentrations ( $p>0.7$, unpaired $t$ test), indicating that hormonal levels of dopamine $\left(10^{-9} \mathrm{M}\right.$ and lower) are not likely to result in considerable desensitization.

\section{Dopamine effects on preparations with intact modulatory input}

To determine how dopamine affects the activity of PD neurons in more realistic pyloric activity patterns, we did bath applications of $10^{-6} \mathrm{M}$ dopamine in preparations with intact modulatory inputs (Fig. 6). This resulted in peripheral spike initiation in 10 of 14 cases $(71 \%)$, with highly variable numbers of antidromic spikes per cycle. Figure $6 A$ shows example traces of intracellular $\mathrm{PD}$ recordings in $10^{-6} \mathrm{M}$ dopamine in three different preparations. Trace 1 shows no peripheral spike initiation, trace 2 shows weak activation with only one antidromic spike per cycle, and trace 3 shows stronger activation of peripheral spike initiation.

In these experiments, the pyloric cycle frequency increased slightly but significantly. This effect was not correlated with antidromic spikes invading the neuropil. Figure $6 B, C$ show plots of the instantaneous cycle frequency over time from a preparation that did not exhibit peripheral spiking (Fig. 6B) and one that did (Fig. 6C). In both cases the cycle frequencies increased with a comparable time course and magnitude. Furthermore, the increase in cycle frequency had an earlier onset than peripheral spike initiation and no additional increase was seen after the appearance of antidromic spikes (Fig. 6C).

In eight preparations we recorded stretches of steady-state cycling in control, $10^{-6} \mathrm{M}$ dopamine and wash long enough to determine the mean cycle frequencies (Fig. 6D). The cycle frequency increased from $0.67 \pm 0.13 \mathrm{~Hz}$ in control to $0.77 \pm 0.16$ $\mathrm{Hz}$ in dopamine (mean $\pm \mathrm{SD}$, paired $t$ test, $p<0.01$ ). We never observed a breakdown of the slow-wave membrane oscillation as described above for preparations with the stn blocked (Fig. 2).

\section{Effect of dopamine on total spike number}

In preparations with intact modulatory input, in which the PD neurons cycled at much faster frequencies compared with preparations with the stn blocked, peripheral spike initiation was less frequent and weaker (Fig. 6A). Furthermore, when peripheral spiking was weak, these spikes were always clustered late in the interburst interval (Fig. $2 B$; trace 2 in Fig. 6A). Therefore, the silences after the bursts suggested that peripheral spike initiation might be suppressed by orthodromic spikes for several hundreds of milliseconds. Conversely, the slow-wave membrane oscillation of the PD neuron in somatic recordings decreased in amplitude and cycle frequency with increased antidromic spiking (Fig. $2 C, D)$, which suggested that spikes invading the neuropil antidromically were suppressing the burst mechanism. Competitive interactions between orthodromic and antidromic spiking are the subject of our unpublished research, but here we describe the relative contribution of centrally and peripherally generated spikes to the overall spike frequency in $10^{-6} \mathrm{M}$ dopamine in two cases: stn blocked and stn intact.

In some experiments, it was possible to sort spikes in the intracellular PD soma recording according to the different conduction delays between the STG and pdn, thus classifying them as centrally or peripherally generated. Figure $7 A$ shows the time course of changes in overall spike frequency as means from three different experiments with the stn blocked. The actual frequencies and the time course of the change in frequencies were so similar in these experiments that bin values were averaged without normalization. Dopamine application caused an approximately fourfold increase in overall spike frequency (from $2.0 \pm$ $0.9 \mathrm{~Hz}$ in control to $7.8 \pm 1.9 \mathrm{~Hz}$ in dopamine, $n=4$, including one experiment in which we could not distinguish between orthodromic and antidromic spikes, paired $t$ test, $p<0.004$ ). This fourfold increase developed over several minutes, whereas the cycle frequency increased less than threefold. This spike frequency increase was attributable primarily to peripheral spiking. Although there was an initial increase in orthodromic spiking with the onset of the increase in cycle frequency, orthodromic spike frequency subsequently decreased steadily and centrally generated spiking ceased eventually. After several minutes, the overall spike frequency leveled off and spikes were almost entirely generated in the periphery, although a slow-wave membrane oscillation of PD was still present.

Orthodromic spiking did not cease during the application of $10^{-6} \mathrm{M}$ dopamine to preparations with intact modulatory inputs. Figure $7 B$ shows overall spike and cycle frequencies from a preparation with relatively strong antidromic spiking (trace 3 in Fig. $6 A$ ). The overall spike frequency increased only slightly with increasing cycle frequency. This increase was attributable to anti- 
A

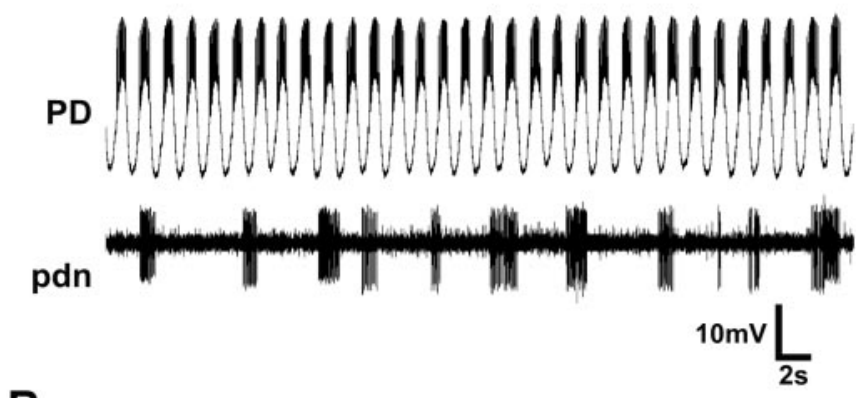

B

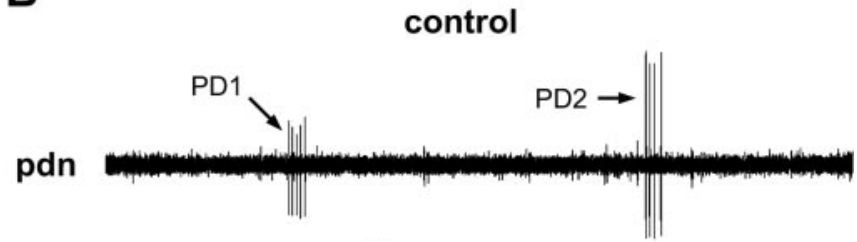

$10^{-9} \mathrm{M}$ dopamine

pdn

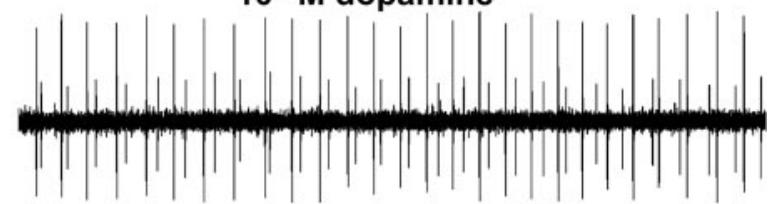

$10^{-6} \mathrm{M}$ dopamine

pdn

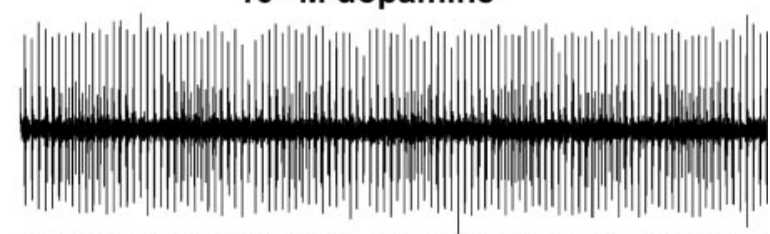

PD1

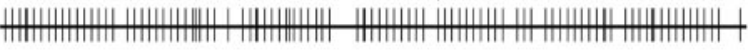

PD2
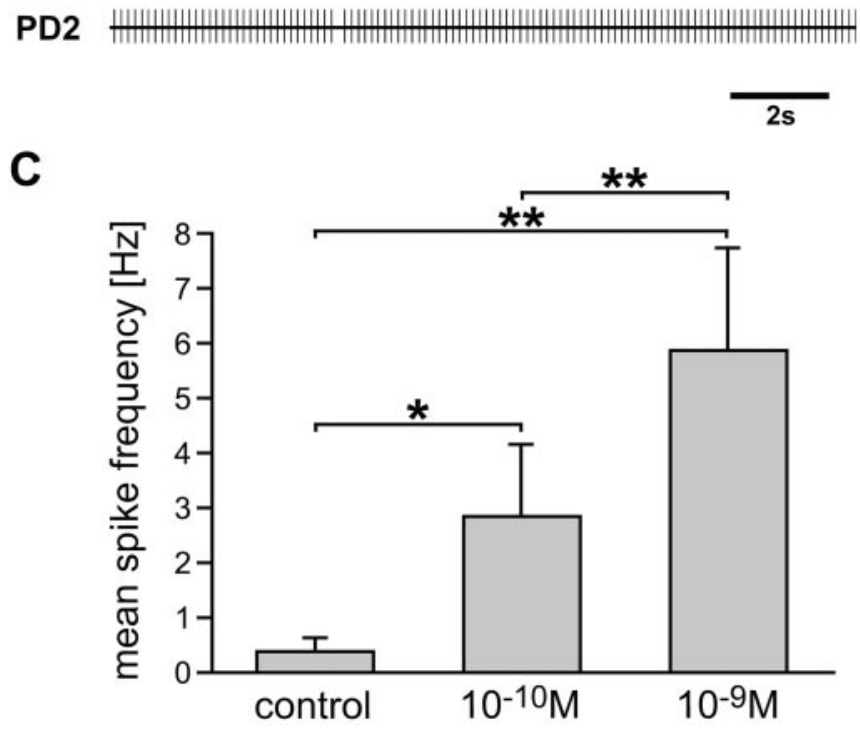

Figure 5. Activity of isolated peripheral PD axons. $A$, TTX/sucrose in dvn well, isolating the STG from the periphery. Under these conditions, central PD neuron activity was uncoupled from the axons, which produced bursts of spikes at a low and irregular frequency. B, First trace, control saline. Both PD axons (which were easily distinguishable by different amplitude spikes) exhibited low-frequency irregular bursting. Second trace, tonic spiking in $10^{-9} \mathrm{M}$ dopamine. Third trace, $10^{-6} \mathrm{M}$ dopamine. Bottom two traces, The extracellular signal was sorted to show the activity of the two PD axons separately. The smaller signal appears to be bursting in the raw trace, but this is only because of shifting intervals between the two different signals. The sorted traces reveal that there is no rhythmic modulation of the spike frequency in either of the two PD neuron axons. C, Increase in spike frequency in isolated peripheral PD axons in low concentra- dromic spiking, because the orthodromic spike frequency decreased over time. However, after several minutes, both antidromic and orthodromic spike frequency remained at a steady level. Although the increase in total overall spike frequency was much smaller in these experiments compared with preparations in which the stn was blocked, the increase was still significant from $8.3 \pm 1.4 \mathrm{~Hz}$ in control to $9.6 \pm 1.3 \mathrm{~Hz}$ (means $\pm S D$, $n=8$, paired $t$ test, $p<0.001$ ). The percentage of increase in spike frequency was not significantly correlated with the increase in cycle frequency (Spearman rank correlation test, $p=0.29$ ).

Taken together, these data show that the total PD neuron spike frequency is relatively unaffected in dopamine when the descending modulatory inputs are intact and the central spike initiation remains active at a steady level, but it is greatly increased by dopamine when the preparations are slowly rhythmic before dopamine application.

\section{Discussion}

Axons are usually thought to be obedient and faithful carriers of information from one place to a distant site. In this work we show that the axons of the PD neurons of the lobster stomatogastric nervous system are more than mere carriers of information, but instead are both sensitive to dopamine and capable of initiating spikes at peripheral sites. This argues that under some conditions these axonal properties will alter the discharge pattern that drives the muscles innervated by these neurons and may modify the central networks in which these neurons are found. How general are these results likely to be? It is possible that many axons in invertebrates may have these capabilities, because there are numerous examples of neurons with multiple spike initiation zones that project into several ganglia (Hughes and Wiersma, 1960; Kennedy and Mellon, 1964; Calabrese, 1980; Dickinson et al., 1981). In this case, it may be advantageous to selectively alter the firing properties of these neurons at many loci. This can be done with local presynaptic contacts (Nusbaum et al., 1992) but could equally well be achieved by axonal neuromodulation. Vertebrate myelinated axons are specialized to conduct action potentials rapidly and precisely from one site to another. However, there are reports that some vertebrate axons are chemosensitive and action potential conduction can be altered by GABA (Alford et al., 1991; Sakatani et al., 1991a, 1991b, 1993; Lim and Ho, 1998; Verdier et al., 2003).

Interactions between multiple spike initiation zones Different spike initiation sites in a single neuron can interact with each other. Suppression of spike initiation at one site by spikes generated at a different site has been found in leech heart motor neurons and intersegmental interneurons (Calabrese, 1980; Maranto and Calabrese, 1983) as well as in cat and crayfish leg proprioceptor afferents (Bevengut et al., 1997; Gossard et al., 1999; Cattaert and Bevengut, 2002). Such interactions could have important implications for the way the actual output of a neuron is shaped. Peripheral spike initiation in the PD neurons also appeared to be suppressed by "normal" spiking activity generated in the STG neuropil. Early in dopamine application, centrally generated bursts were followed by a period of silence before peripheral spikes were generated again, and only a subset of the prepa-

$\leftarrow$

tions of dopamine. Dopamine application caused a significant increase in spike frequency $(n=12$; $p<0.01$, Friedman test). Spike frequencies were significantly different between control and $10^{-10}$ M dopamine $\left(p<0.05\right.$, Wilcoxon signed rank test), control and $10^{-9} \mathrm{M}$ dopamine $(p<0.01)$, and $10^{-10} \mathrm{M}$ and $10^{-9} \mathrm{M}$ dopamine $(p<0.01)$. Data are shown as means \pm SEM. 
A intact modulatory inputs, $10^{-6} \mathrm{M}$ dopamine

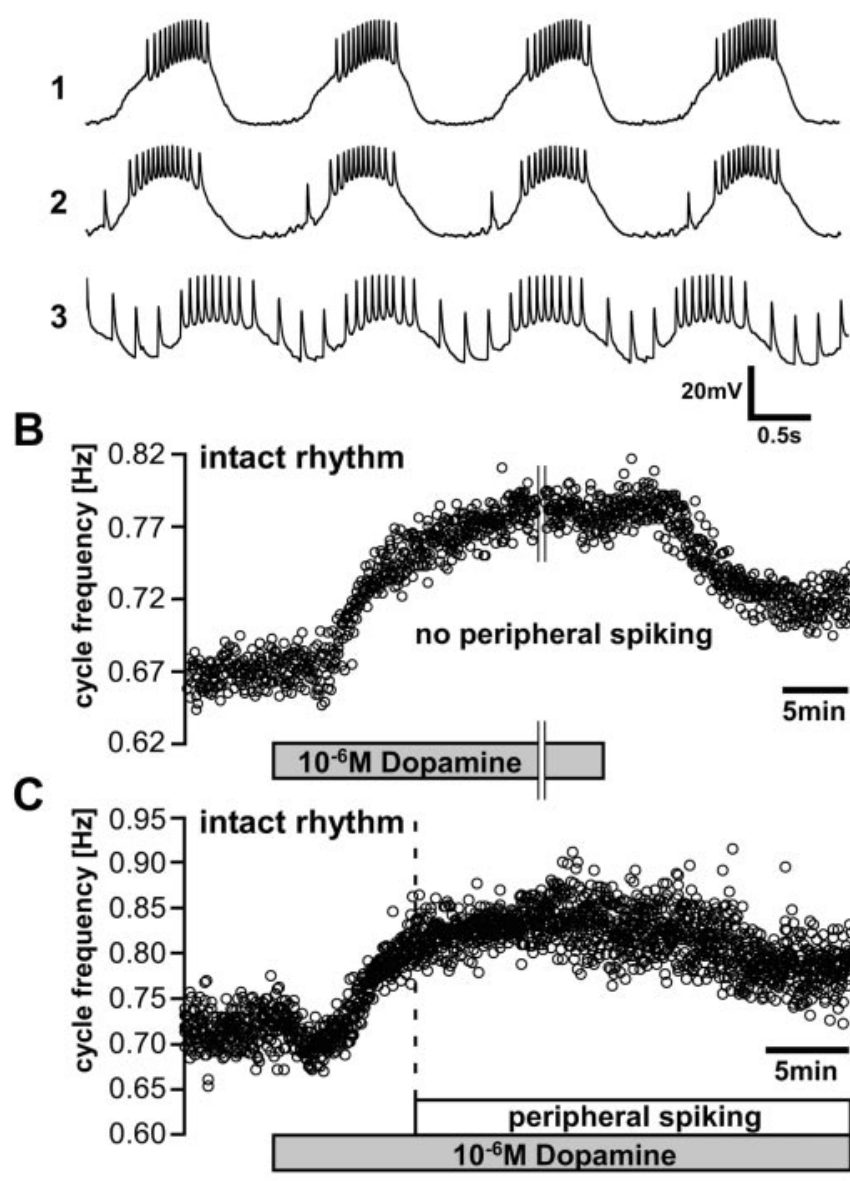

D

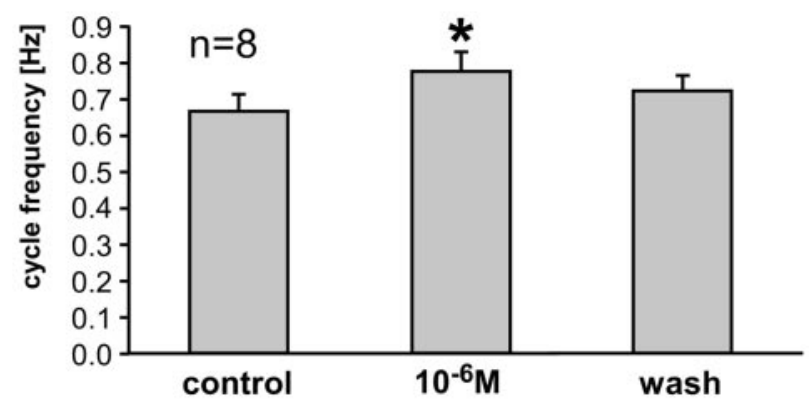

Figure 6. Bath application of dopamine to preparations with intact modulatory inputs. A, Intracellular recordings of PD neuron activity in $10^{-6} \mathrm{M}$ dopamine from three different preparations $(1,2,3) . B, C$, Instantaneous cycle frequencies over time. Dopamine application increased cycle frequency regardless of peripheral spike initiation. The onset of the increase in cycle frequency was always earlier than the appearance of antidromic spikes, and there was no additional increase in cycle frequency after the onset of peripheral spiking. D, Mean cycle frequencies for eight preparations. Cycle frequency in dopamine was significantly increased compared with the control ( $p<0.01, n=8$, paired $t$ test).

rations with rapid control rhythms exhibited peripheral spikes. In addition, spikes generated in the periphery may also have an inhibitory effect on central spike initiation (Fig. 2C,D).

Intrinsic bursting properties of the PD neuron axons

As in leech heart motor neurons (Maranto and Calabrese, 1983), removal of central activity rapidly initiated bursting activity in the PD axons (Fig. 5). The function of this inherent bursting capability of the peripheral axon is not clear, but it may assist in
A

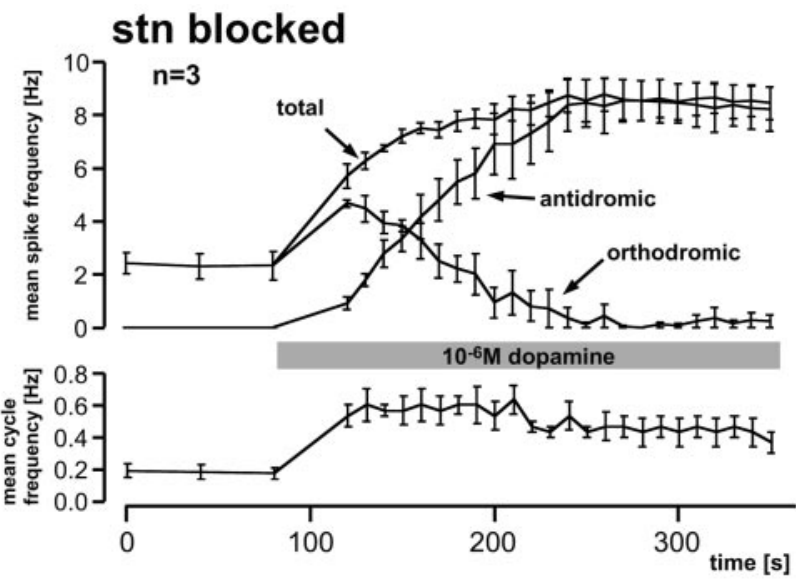

B
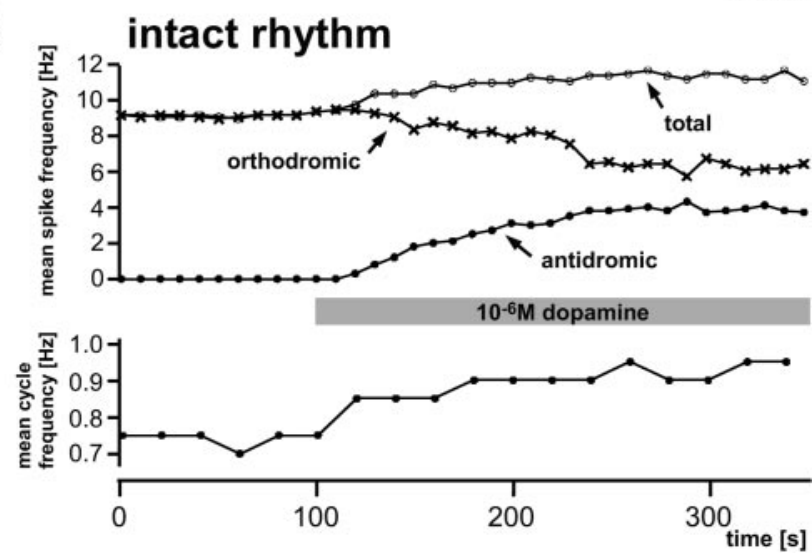

Figure 7. Relative contribution of antidromic and orthodromic spikes to the overall spike frequency in $10^{-6} \mathrm{M}$ dopamine. Intracellularly recorded spikes were sorted according to different conduction delays between STG and pdn using a delay filter algorithm. $A$, Average bin values ( \pm SEM) of mean spike frequency and cycle frequency from three preparations with modulatory inputs from the CoGs and the $\mathrm{OG}$ removed by blocking impulse activity in the stn with TTX/sucrose. At the beginning of dopamine application (gray bar), the overall total spike frequency increased because of an increase of orthodromic spike frequency with increasing cycle frequency. Later, the contribution of orthodromic spiking to the overall spike frequency decreased and antidromic spiking increased. $B$, In a preparation with intact modulatory input and relatively strong antidromic spiking (Fig. $6 A$, trace 3), the orthodromic spike frequency decreased with increasing antidromic spike frequency, whereas the cycle frequency increased. Orthodromic spiking did not cease, and both orthodromic and antidromic spike frequencies eventually reached a steady level.

the conduction of bursting activity generated centrally (Maranto and Calabrese, 1983).

Dopamine most likely acts as a neurohormone on the peripheral PD neuron axons

What is the source of dopamine for spike initiation in the peripheral PD neuron axons? Dopamine is present both in the hemolymph and in modulatory terminals in the STG neuropil, but there are no indications that it is present in the peripheral motor nerves (Kushner and Maynard, 1977; Kushner and Barker, 1983; Cournil et al., 1994, 1995; Pulver et al., 2003). We found peripheral spike initiation in response to bath-applied concentrations of dopamine similar to those measured for other hormones (Livingstone et al., 1980). Therefore, the low threshold for dopamine action makes hormonal modulation by dopamine plausible. The presence of dopamine in the pericardial organs of crustaceans has been well established (Cooke and Goldstone, 1970; Goldstone and Cooke, 1971; Siwicki et al., 1987; Pulver and Marder, 2002). Interestingly, the main source of dopamine in the pericardial 
organ is the L-cell, the largest neuron in the CoGs. One might speculate that the L-cell receives synaptic inputs in the CoG from neurons that are part of the modulatory control system of the stomatogastric neurons and in so doing control the hormonal liberation of dopamine as part of the regulation of food processing.

The low threshold for spike initiation was found when we applied dopamine to the whole periphery. In focal applications to small sections of nerve, such low concentrations were ineffective. We made no attempt to determine the actual threshold concentrations needed in small wells, but used saturating concentrations. Many dopamine receptors are G-protein-coupled and regulate cAMP levels (Gingrich and Caron, 1993; Jackson and Westlind-Danielsson, 1994). Therefore, it is easy to imagine that the application of dopamine to a small area of axon is effective only at higher concentrations because second messengers diffuse in axial directions. In addition, even if second-messengers levels are efficiently altered, actions on membrane currents confined to the site of application are less efficient in triggering spikes because the current spread up and down the axon will cause a smaller voltage response compared with a situation in which the whole axon is targeted by dopamine.

\section{Effects of dopamine on the pyloric central pattern generator}

The effects of dopamine application on the activity of the pyloric central pattern generator have been described extensively in the spiny lobster, P. interruptus (Harris-Warrick et al., 1998). The effect of dopamine application on the pacemaker kernel in $P$. interruptus is complex, because it has different actions on the electrically coupled PD and AB neurons (Marder and Eisen, 1984; Flamm and Harris-Warrick, 1986b). It hyperpolarizes the PD neurons and reduces spike frequency. At the same time, it has an excitatory effect on the $\mathrm{AB}$ neuron. Therefore, at any time, the net effect of dopamine is a reflection of opposing effects that on average result in a small decrease in pyloric cycle frequency (Ayali and Harris-Warrick, 1999). In H. americanus, we found a consistent increase in pyloric cycle frequency even in the absence of antidromic spikes. However, detailed comparisons between the effects of dopamine in the two species are impossible because most of the data in P. interruptus were collected using $10^{-4} \mathrm{M}$ dopamine, whereas our data were collected using $10^{-6} \mathrm{M}$ dopamine and lower because rhythmic activity rapidly and completely ceased in higher concentrations.

In $P$. interruptus, antidromic nerve stimulations have been shown to fail to evoke synaptic potentials in postsynaptic neurons (Mulloney and Selverston, 1972), and in the crab LG neuron, antidromic spikes evoked by the application of serotonin have no effect on LG target cells in the STG (Meyrand et al., 1992). We did not test if the same is true for the PD neurons in H. americanus because spike-mediated IPSPs are usually not seen in soma recordings of neurons postsynaptic to the PD neurons (Fig. 2) (Thirumalai and Marder, 2002). However, if antidromic spikes affect the membrane potential and bursting properties of the PD neurons (Fig. 2), this may change the transmitter release of the $\mathrm{PD}$ neurons and indirectly lead to changes in the phase relationships between pyloric neurons.

Dopamine effects have not been studied extensively in the stomatogastric nervous system of the crab, Cancer borealis. However, some preliminary results (Marder and Weimann, 1992) suggest similarities to $H$. americanus. In C. borealis, $10^{-6} \mathrm{M}$ dopamine also elicits tonic spiking in the PD neurons, although it is not known where these spikes are generated.

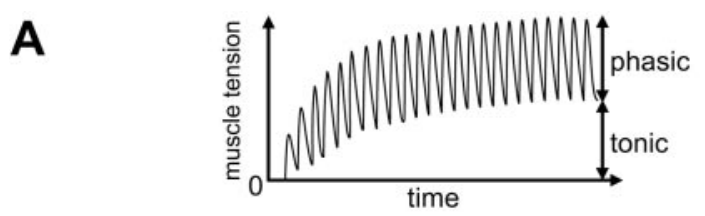

\section{B cycle frequency: $1 \mathrm{~Hz}$ cycle frequency: $0.4 \mathrm{~Hz}$ control}

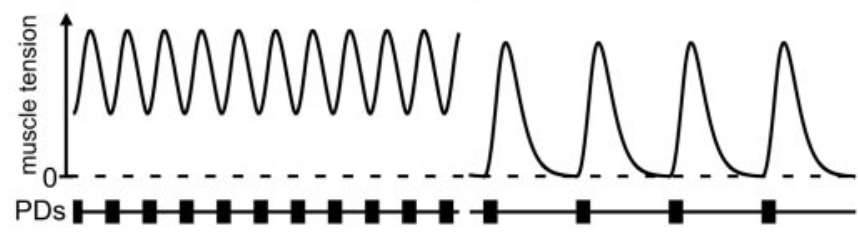

C

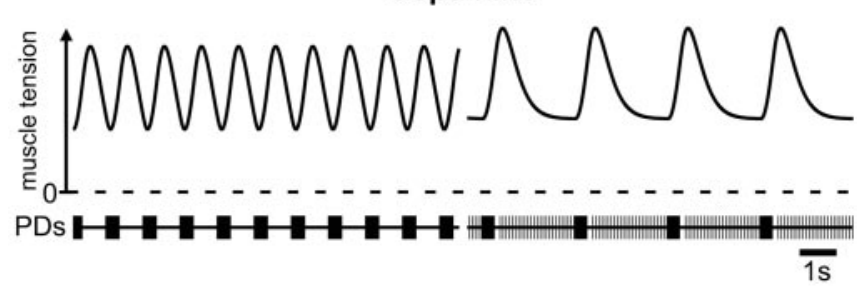

Figure 8. Diagram of potential consequences of $\mathrm{PD}$ axon peripheral spike initiation for muscle contraction. $A$, In a muscle with slow contraction dynamics the tension summates at normal pyloric cycle frequencies. At steady state, phasic contractions ride on top of a tonic baseline tension. The relative amplitudes of the tonic and phasic responses are dependent on the cycle frequency of the bursting input. Modified from Morris and Hooper (1998) and Hooper and Weaver (2000). B, As the rhythmic input decreases in frequency the phasic contractions increase and the tonic contraction decreases. C, If peripheral spike initiation increases with lowered cycle frequencies, the tonic spiking during the interburst intervals provides a means to keep tonic muscle tension at a comparable level, whereas the timing of bursting input is changed.

\section{Functional implications of peripheral spike initiation in PD} for muscle contractions

The spikes generated in the PD neuron axons are antidromic from the perspective of the PD neuron soma recordings, but they travel both up to the STG and down the axons to the pdn, which innervates a subset of the pyloric dilator muscles (Maynard and Dando, 1974). Ultimately, changes in motor neuron activity result in different movements only if the muscles can follow these changes. For example, serotonin-evoked low-frequency spiking after a burst in the LG neuron in the crab stomatogastric system leads to a sustained contraction in only one of the three muscles innervated by LG (Meyrand et al., 1992).

Work in many systems has shown that the neuron-to-muscle transform is nonlinear (Morris and Hooper, 1997, 1998, 2001; Brezina et al., 2000; Brezina and Weiss, 2000; Hooper and Weaver, 2000). Many invertebrate muscles, including crustacean stomach muscles, have slow contraction dynamics. Some of the muscles innervated by the PD neurons in P. interruptus show slow relaxation properties that lead to temporal summation of muscle tension (Morris and Hooper, 1997, 1998, 2001). Consequently, bursting input is transformed into phasic contractions that ride on top of a tonic baseline tension (Fig. $8 \mathrm{~A}$ ). The relative amplitudes of the tonic and phasic components are critically dependent on the burst frequency of the neural input. The tonic component decreases in amplitude at lower cycle frequencies and the phasic component increases (Fig. $8 B$ ). In slow muscles, ex- 
traburst tonic spiking like we found in the PD neurons in $H$. americanus is likely to change both the average contraction amplitude and the ratio between tonic and phasic components. Because of suppression of peripherally initiated spikes by centrally generated spikes this effect may be predominantly present at low cycle frequencies (Fig. $8 C$ ). In summary, our data suggest that hormonally liberated dopamine could ensure that adequate muscle tone is maintained even at low pyloric cycle frequencies by activating axonal dopamine receptors and triggering peripheral spikes to fill in motor neuron discharge during long interburst intervals.

\section{References}

Alford S, Christenson J, Grillner S (1991) Presynaptic GABA ${ }_{A}$ and GABA $_{B}$ receptor-mediated phasic modulation in axons of spinal motor interneurons. Eur J Neurosci 3:107-117.

Ayali A, Harris-Warrick RM (1998) Interaction of dopamine and cardiac sac modulatory inputs on the pyloric network in the lobster stomatogastric ganglion. Brain Res 794:155-161.

Ayali A, Harris-Warrick RM (1999) Monoamine control of the pacemaker kernel and cycle frequency in the lobster pyloric network. J Neurosci 19:6712-6722.

Ayali A, Johnson BR, Harris-Warrick RM (1998) Dopamine modulates graded and spike-evoked synaptic inhibition independently at single synapses in pyloric network of lobster. J Neurophysiol 79:2063-2069.

Barker DL, Kushner PD, Hooper NK (1979) Synthesis of dopamine and octopamine in the crustacean stomatogastric nervous system. Brain Res 161:99-113.

Bässler U (1984) A movement generated in the peripheral nervous system, rhythmic flexion of autotomized legs of the stick insect Cuniculina impigra. J Exp Biol 111:191-199.

Bevengut M, Clarac F, Cattaert D (1997) Antidromic modulation of a proprioceptor sensory discharge in crayfish. J Neurophysiol 78:1180-1183.

Brezina V, Weiss KR (2000) The neuromuscular transform constrains the production of functional rhythmic behaviors. J Neurophysiol 83:232-259.

Brezina V, Orekhova IV, Weiss KR (2000) The neuromuscular transform: the dynamic, nonlinear link between motor neuron firing patterns and muscle contraction in rhythmic behaviors. J Neurophysiol 83:207-231.

Calabrese RL (1980) Control of multiple impulse-initiation sites in a leech interneuron. J Neurophysiol 44:878-896.

Cattaert D, Bevengut M (2002) Effects of antidromic discharges in crayfish primary afferents. J Neurophysiol 88:1753-1765.

Christie AE, Skiebe P, Marder E (1995) Matrix of neuromodulators in neurosecretory structures of the crab Cancer borealis. J Exp Biol 198:2431-2439.

Connor JA, Walter D, McKown R (1977) Neural repetitive firing: modifications of the Hodgkin-Huxley axon suggested by experimental results from crustacean axons. Biophys J 18:81-102.

Cooke IM, Goldstone MW (1970) Fluorescence localization of monoamines in crab neurosecretory structures. J Exp Biol 53:651-668.

Cournil I, Helluy SM, Beltz BS (1994) Dopamine in the lobster Homarus gammarus. I. Comparative analysis of dopamine and tyrosine hydroxylase immunoreactivities in the nervous system of the juvenile. J Comp Neurol 344:455-469.

Cournil I, Casasnovas B, Helluy SM, Beltz BS (1995) Dopamine in the lobster Homarus gammarus: II. Dopamine-immunoreactive neurons and development of the nervous system. J Comp Neurol 362:1-16.

Dickinson PS, Nagy F, Moulins M (1981) Interganglionic communication by spiking and nonspiking fibers in same neuron. J Neurophysiol 45:1125-1138.

Dudel J (1965) Facilitory effects of 5-hydroxy-tryptamine on the crayfish neuromuscular junction. Arch Exp Pathol Pharmakol 249:515-528.

Flamm RE, Harris-Warrick RM (1986a) Aminergic modulation in lobster stomatogastric ganglion. I. Effects on motor pattern and activity of neurons within the pyloric circuit. J Neurophysiol 55:847-865.

Flamm RE, Harris-Warrick RM (1986b) Aminergic modulation in lobster stomatogastric ganglion. II. Target neurons of dopamine, octopamine, and serotonin within the pyloric circuit. J Neurophysiol 55:866-881.

Gingrich JA, Caron MG (1993) Recent advances in the molecular biology of dopamine receptors. Annu Rev Neurosci 16:299-321.

Goldstone MW, Cooke IM (1971) Histochemical localization of mono- amines in the crab central nervous system. Z Zellforsch Mikrosk Anat 116:7-19.

Gossard JP, Bouyer L, Rossignol S (1999) The effects of antidromic discharges on orthodromic firing of primary afferents in the cat. Brain Res 825:132-145.

Grundfest H, Reuben JP (1961) Neuromuscular synaptic activity in lobster. In: Nervous inhibition (Florey E, ed), pp 92-104. New York: Pergamon.

Harris-Warrick R, Marder E, Selverston A, Moulins M, eds (1992) Dynamic biological networks: the stomatogastric nervous system. Cambridge, MA: MIT Press.

Harris-Warrick RM, Johnson BR, Peck JH, Kloppenburg P, Ayali A, Skarbinski J (1998) Distributed effects of dopamine modulation in the crustacean pyloric network. Ann N Y Acad Sci 860:155-167.

Hartline DK, Graubard K (1992) Cellular and synaptic properties in the crustacean stomatogastric nervous system. In: Dynamic biological networks: the stomatogastric nervous system. (Harris-Warrick R, Marder E, Selverston A, Moulins M, eds). Cambridge, MA: MIT Press.

Hodgkin AL, Huxley AF (1952) A quantitative description of membrane current and its application to conduction and excitation in nerve. J Physiol (Lond) 117:500-544.

Hooper SL, Weaver AL (2000) Motor neuron activity is often insufficient to predict motor response. Curr Opin Neurobiol 10:676-682.

Hughes GM, Wiersma CAG (1960) Neuronal pathways and synaptic connexions in the abdominal nerve cord of the crayfish. J Exp Biol 37:291-307.

Jackson DM, Westlind-Danielsson A (1994) Dopamine receptors: molecular biology, biochemistry and behavioural aspects. Pharmacol Ther 64:291-370.

Kennedy D, Mellon DF (1964) Synaptic activation and receptive fields in crayfish interneurones. Comp Biochem Physiol 13:275-300.

Kloppenburg P, Levini RM, Harris-Warrick RM (1999) Dopamine modulates two potassium currents and inhibits the intrinsic firing properties of an identified motor neuron in a central pattern generator network. J Neurophysiol 81:29-38.

Kloppenburg P, Zipfel WR, Webb WW, Harris-Warrick RM (2000) Highly localized $\mathrm{Ca}^{2+}$ accumulation revealed by multiphoton microscopy in an identified motoneuron and its modulation by dopamine. J Neurosci 20:2523-2533.

Kushner P, Barker DL (1983) A neurochemical description of the dopaminergic innervation of the stomatogastric ganglion of the spiny lobster. J Neurobiol 14:17-28.

Kushner PD, Maynard EA (1977) Localization of monamine fluorescence in the stomatogastric nervous system of lobsters. Brain Res 129:13-28.

Lim CH, Ho SM (1998) GABAergic modulation of axonal conduction in the developing rat retinotectal pathway. Brain Res Dev Brain Res 108:299-302.

Livingstone MS, Harris-Warrick RM, Kravitz EA (1980) Serotonin and octopamine produce opposite postures in lobsters. Science 208:76-79.

Maranto AR, Calabrese RL (1983) Neural control of the hearts in the leech, Hirudo medicinales. II. Myogenic activity and its control by heart motoneurons. J Comp Physiol A 154:381-391.

Marder E (1987) Neurotransmitters and neuromodulators. In: The crustacean stomatogastric system. (Selverston AI, Moulins M, eds), pp 263-300. Berlin: Springer.

Marder E, Bucher D (2001) Central pattern generators and the control of rhythmic movements. Curr Biol 11:R986-996.

Marder E, Calabrese RL (1996) Principles of rhythmic motor pattern generation. Physiol Rev 76:687-717.

Marder E, Eisen JS (1984) Electrically coupled pacemaker neurons respond differently to same physiological inputs and neurotransmitters. J Neurophysiol 51:1362-1374.

Marder E, Weimann JM (1992) Modulatory control of multiple task processing in the stomatogastric nervous system. In: Neurobiology of motor progamme selection (Kien J, McCrohan C, Winlow B, eds), pp 3-19. New York: Pergamon.

Marder E, Christie AE, Kilman VL (1995) Functional organization of cotransmission systems: lessons from small nervous systems. Invert Neurosci 1:105-112.

Maynard DM, Dando MR (1974) The structure of the stomatogastric neuromuscular system in Callinectes sapidus, Homarus americanus and Panulirus argus (Decapoda Crustacea). Philos Trans R Soc Lond B 268:161-220.

Meyrand P, Weimann JM, Marder E (1992) Multiple axonal spike initiation zones in a motor neuron: serotonin activation. J Neurosci 12:2803-2812. 
Morris LG, Hooper SL (1997) Muscle response to changing neuronal input in the lobster (Panulirus interruptus) stomatogastric system: spike number- versus spike frequency-dependent domains. J Neurosci 17:5956-5971.

Morris LG, Hooper SL (1998) Muscle response to changing neuronal input in the lobster (Panulirus interruptus) stomatogastric system: slow muscle properties can transform rhythmic input into tonic output. J Neurosci 18:3433-3442.

Morris LG, Hooper SL (2001) Mechanisms underlying stabilization of temporally summated muscle contractions in the lobster (Panulirus) pyloric system. J Neurophysiol 85:254-268.

Mulloney B, Selverston A (1972) Antidromic action potentials fail to demonstrate known interactions between neurons. Science 177:69-72.

Nusbaum MP, Weimann JM, Golowasch J, Marder E (1992) Presynaptic control of modulatory fibers by their neural network targets. J Neurosci 12:2706-2714.

Peck JH, Nakanishi ST, Yaple R, Harris-Warrick RM (2001) Amine modulation of the transient potassium current in identified cells of the lobster stomatogastric ganglion. J Neurophysiol 86:2957-2965.

Pulver SR, Marder E (2002) Neuromodulatory complement of the pericardial organs in the embryonic lobster, Homarus americanus. J Comp Neurol 451:79-90.

Pulver SR, Thirumalai V, Richards KS, Marder E (2003) Dopamine and histamine in the developing stomatogastric system of the lobster, Homarus americanus. J Comp Neurol 462:400-414.

Russell DF, Graubard K (1987) Cellular and synaptic properties. In: The crustacean stomatogastric system (Selverston AI, Moulins M, eds). Berlin: Springer.

Sakatani K, Hassan AZ, Ching W (1991a) Age-dependent extrasynaptic modulation of axonal conduction by exogenous and endogenous GABA in the rat optic nerve. Exp Neurol 114:307-314.

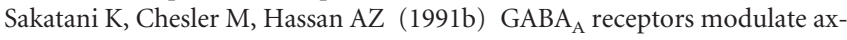
onal conduction in dorsal columns of neonatal rat spinal cord. Brain Res 542:273-279.

Sakatani K, Chesler M, Hassan AZ, Lee M, Young W (1993) Non-synaptic modulation of dorsal column conduction by endogenous GABA in neonatal rat spinal cord. Brain Res 622:43-50.

Schmidt J, Grund M (2001) Axotomy-induced rhythmic bursting in a motor axon. In: Proceedings of the 4th meeting of the German Neuroscience Society (Elsner N, Kreutzberg GW, eds), p 352. Stuttgart: Thieme.

Selverston AI, Moulins M, eds (1987) The crustacean stomatogastric system. Berlin: Springer.

Siwicki KK, Beltz BS, Kravitz EA (1987) Proctolin in identified serotonergic, dopaminergic, and cholinergic neurons in the lobster, Homarus americanus. J Neurosci 7:522-532.

Standaert FG (1963) Post-tetanic repetitive activity in the cat soleus nerve: its origin, course, and mechanism of generation. J Gen Physiol 47:53-70.

Standaert FG (1964) The mechanisms of post-tetanic potentiation in cat soleus and gastrocnemius muscles. J Gen Physiol 47:987-1001.

Sullivan RE (1978) Stimulus-coupled ${ }^{3} \mathrm{H}$-serotonin release from identified neurosecretory fibers in the spiny lobster, Panulirus interruptus. Life Sciences 22:1429-1438.

Thirumalai V, Marder E (2002) Colocalized neuropeptides activate a central pattern generator by acting on different circuit targets. J Neurosci 22:1874-1882.

Verdier D, Lund JP, Kolta A (2003) GABAergic control of action potential propagation along axonal branches of mammalian sensory neurons. J Neurosci 23:2002-2007. 